\title{
CLINICO-PATHOLOGICAL STUDY OF NON-VENEREAL GENITAL DERMATOSES
}

\author{
Kurimila Narasimha Prasad1, Vangali Srikanth Reddy², Boppani Praveen Kumar ${ }^{3}$, JVDS Prasad4 \\ ${ }^{1}$ Assistant Professor, Department of DVL, Osmania Medical College, Hyderabad, Telangana, India. \\ ${ }^{2}$ Senior Resident, Department of DVL, Osmania Medical College, Hyderabad, Telangana, India. \\ $3 J u n i o r$ Resident, Department of DVL, Osmania Medical College, Hyderabad, Telangana, India. \\ ${ }^{4}$ Professor, Department of DVL, Osmania Medical College, Hyderabad, Telangana, India.
}

\section{BACKGROUND}

ABSTRACT

Non-Venereal Dermatoses tend to be confused with Venereal Diseases, which may be responsible for considerable concern to the patients as well as causing diagnostic dilemma to the Physicians. The study was to find the pattern of Non-Venereal Dermatoses presenting with genital lesions and to compare with the clinical and histopathological diagnosis.

\section{MATERIALS AND METHODS}

The study included 100 patients of both sexes attending the OPD of Department of DVL of Osmania General Hospital, Hyderabad, presenting with genital lesions, orogenital lesions, genital and skin lesions and orogenital and skin lesions of Non-Venereal conditions presenting over a period of 18 months from Dec 2013 to Jun 2015. Data was collected from the selected subjects by recording relevant patient details and a thorough general, systemic and dermatological examination. All cases were subjected to thorough clinical examination and investigations.

\section{RESULTS}

The prevalence of Non-Venereal Genital lesion during the period was found to be 4.1 per 1000 patients attending DVL Department. The most common disorder was genital vitiligo, which accounted for 21 patients (21\%) followed by scabies in 19 (19\%) and Lichen planus in 10 (10\%). The other major disorders encountered included pemphigus vulgaris in 10 (10\%), FDE in 8 (8\%), pearly penile papules and LSEA each in $5(5 \%)$ patients. Scabies $19(24.35 \%)$ and genital vitiligo 15 patients (19.23\%) were the two most common disorders seen in the male population, whereas genital vitiligo in $6(27.27 \%)$ and pemphigus vulgaris in 6 (27.27\%) were common disorders seen among female population.

\section{CONCLUSION}

In the present study, there was a high correlation with confirmation of clinical diagnosis to histological diagnosis except in two cases where the findings resulted in a change in the diagnosis. Most dermatoses of the genitalia are amicable to clinical diagnosis based on classic dermatological grounds of full history taking and complete physical examination. Biopsies need not be performed routinely, although they may be useful in confirming the clinical diagnosis. Secondly, a histological diagnosis may be valuable in advancing patient management.

\section{KEY WORDS}

Non-Venereal, Genital, Vitiligo, Scabies.

HOW TO CITE THIS ARTICLE: Prasad KN, Reddy VS, Kumar BP. Clinico-pathological study of non-venereal genital dermatoses. J. Evolution Med. Dent. Sci. 2018;7(21):2609-2616, DOI: 10.14260/jemds/2018/587

\section{BACKGROUND}

Non-Venereal Dermatoses tend to be confused with Venereal Diseases, which may be responsible for considerable concern to the patients as well as causing diagnostic dilemma to the physicians. The study was to find the pattern of Non-Venereal Dermatoses presenting with genital lesions and to compare with the clinical and histopathological diagnosis.

Contrary to popular belief that all lesions on the genitalia are not manifestations of sexually transmitted diseases. These non-venereal disorders are a cause of considerable concern to patients, thus causing mental distress and guilt feelings in them who attribute that they have acquired STD's.

'Financial or Other Competing Interest': None.

Submission 29-03-2018, Peer Review 01-05-2018,

Acceptance 07-05-2018, Published 21-05-2018.

Corresponding Author:

Vangali Srikanth Reddy,

H. No. 4-9-9, Huda Colony, MMRC

Bahadurpura Post,

Hyderabad-500064,

Telangana, India.

E-mail: srikanthjagadam@gmail.com

DOI: $10.14260 /$ jemds $/ 2018 / 587$
Non-Venereal Dermatoses often cause diagnostic dilemma to the treating Physician, who has to effectively manage the condition and also allay the associated anxiety. A comprehensive understanding of the various presentations, their causes and appropriate management options are therefore essential. Determining any causal or aggravating factor can save the patient from the agony of persistent discomfort and restricted social life, thereby considerably improving their quality of life in all the ways.

Non-Venereal Dermatoses need not be restricted to the genitalia alone. It may affect other mucous membranes and also the skin. ${ }^{1}$ Hence, this study was conducted to determine patterns of Non-Venereal Dermatoses presenting with genital lesions and to compare clinical and the histopathological correlation in the confirmation of diagnosis.

\section{MATERIALS AND METHODS} Study Pattern and Source of Data

It was a descriptive study conducted from the patients attending the OPD, Department of DVL of Osmania General Hospital, Hyderabad in the period of 18 months from Dec 2013 to Jun 2015. 


\section{Inclusion Criteria}

Patients with the Non-Venereal lesions of only genital, genital and skin, oro-genital and concurrent oro-genital and skin manifestations were included in the study. Some venereal conditions, which were transmitted through non-venereal routes were also included.

\section{Exclusion Criteria}

Cases having any venereal diseases were excluded from the study.

\section{Evaluation}

For the study detailed history including the age, occupation, history of exposure, duration of the disease and the site involved were taken. Physical examination was done in all cases to see any associated lesions elsewhere in the body. Biopsy was done in only 73 cases, as the rest of the cases were not willing for biopsy. Investigations like $\mathrm{KOH}$ mount, Gram's stain were done wherever it is required to establish the diagnosis. The patients satisfying the inclusion and exclusion criterion as mentioned were taken for the study after an informed written consent. The study included 100 patients of both sexes presenting with genital lesions, orogenital lesions, genital and skin lesions and oro-genital and skin lesions of Non-Venereal conditions presenting over a period of 18 months from Dec 2013 to Jun 2015. Data was collected from the selected subjects by recording relevant patient details and a thorough general, systemic and dermatological examinations were done. A proforma was prepared to record the relevant details of the patient, examination, biopsy report, investigation results and the diagnosis. Disease wise comparison was done for both sexes. The data was finally tabulated and analysed.

\section{RESULTS/Prevalence}

The prevalence of Non-Venereal Genital lesion during the period was found to be 4.1 per 1000 patients attending DVL Department.

\begin{tabular}{|c|c|c|}
\hline Age Group & $\mathbf{M}$ & $\mathbf{F}$ \\
\hline $0-10$ & 1 & - \\
\hline $11-20$ & 4 & 1 \\
\hline $21-30$ & 15 & 3 \\
\hline $31-40$ & 19 & 7 \\
\hline $41-50$ & 18 & 4 \\
\hline $51-60$ & 15 & 6 \\
\hline $61-70$ & 6 & 1 \\
\hline Total & 78 & 22 \\
\hline
\end{tabular}

The age ranged from 9 years to 67 years with the mean age of 41.34 years and median age of 41.5 years. Majority of the patients were in the age group of $31-40(26 \%)$ followed by $41-50(22 \%)$.

The age among the male population ranged from 9 years to 67 years, while that of female ranged from 11 years to 65 years with the mean age of 41.24 years and 41.68 years respectively. The median age of male was 41.5 years, whereas that of female was 41 years. The majority of patients were in the age group of 31 - 40 years (19 patients) and 31 - 40 years (7 patients) for male and female patients respectively in the study group. The male: female ratio in the study population was 3.54: 1 .

\begin{tabular}{|c|c|c|c|}
\hline $\begin{array}{c}\text { Genital Alone } \\
\text { (\%) }\end{array}$ & $\begin{array}{c}\text { Genital and } \\
\text { Skin (\%) }\end{array}$ & $\begin{array}{c}\text { Oro-Genital } \\
\text { (\%) }\end{array}$ & $\begin{array}{c}\text { Oro-Genital } \\
\text { and Skin (\%) }\end{array}$ \\
\hline $42(42)$ & $26(26)$ & $21(21)$ & $11(11)$ \\
\hline Table 2. Classification of Non-Venereal Genital Lesions \\
based on Sites of Involvement \\
\hline
\end{tabular}

The non-venereal genital lesions were grouped into four groups according to the involvement of sites affected as genital, oro-genital, genital and skin and concurrent orogenital and skin lesions. In this study, genital alone comprised of 42 (42\%) accounting for the majority followed by genital and skin in 26 (26\%), oro-genital in 21 (21\%) and oro-genital and skin in 11 (11\%). Involvement of genitalia alone was found to be significantly higher than other groups.

\begin{tabular}{|c|c|c|c|}
\hline Genital Lesions & Total & $\begin{array}{c}\text { Male } \\
(\%)\end{array}$ & $\begin{array}{c}\text { Females } \\
(\%)\end{array}$ \\
\hline \multicolumn{4}{|l|}{ Variants } \\
\hline PPP & $5(11.90)$ & $\begin{array}{c}5 \\
(14.28)\end{array}$ & - \\
\hline Lichen nitidus & $2(4.76)$ & $2(5.71)$ & - \\
\hline Angiokeratoma of Fordyce & $1(2.38)$ & $1(2.85)$ & - \\
\hline Fordyce spots & $3(7.14)$ & $3(8.57)$ & - \\
\hline Penile lentigines & $1(2.38)$ & $1(2.85)$ & - \\
\hline \multicolumn{4}{|l|}{ Infections and Infestations } \\
\hline Scabies & $\begin{array}{c}11 \\
(26.19)\end{array}$ & $\begin{array}{c}11 \\
(31.42)\end{array}$ & - \\
\hline Candidal Balanoposthitis & $1(2.38)$ & $1(2.85)$ & - \\
\hline \multicolumn{4}{|l|}{ Inflammatory Conditions } \\
\hline Fixed Drug Eruption & $2(4.76)$ & $2(5.71)$ & - \\
\hline $\begin{array}{c}\text { Lichen sclerosus atrophicus } \\
\text { or } \\
\text { Balanitis xerotica obliterans }\end{array}$ & $5(11.90)$ & $\begin{array}{c}1 \\
(2.85)\end{array}$ & $\begin{array}{c}4 \\
(57.14)\end{array}$ \\
\hline Zoon's balanitis & $2(4.76)$ & $2(5.71)$ & - \\
\hline \multicolumn{4}{|l|}{ Miscellaneous } \\
\hline Vitiligo & $7(16.66)$ & $\begin{array}{c}4 \\
(11.42) \\
\end{array}$ & $\begin{array}{c}3 \\
(42.85) \\
\end{array}$ \\
\hline Scrotal calcinosis & $1(2.38)$ & $1(2.85)$ & - \\
\hline Sebaceous cyst & $1(2.38)$ & $1(2.85)$ & - \\
\hline Total & $\begin{array}{c}42 \\
(100)\end{array}$ & $\begin{array}{c}35 \\
(83.33)\end{array}$ & $\begin{array}{c}7 \\
(16.66)\end{array}$ \\
\hline & 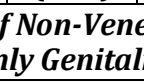 & eal Lesic & \\
\hline
\end{tabular}

Among the non-venereal conditions those involved only genitalia, majority was constituted by scabies in 11 patients (26.19\%) followed by genital vitiligo in 7 (16.6\%) and pearly penile papules in $5(11.9 \%)$. A similar pattern was seen for involvement of male genitalia, whereas LSEA in 4 (57.14\%) and genital vitiligo in $3(42.8 \%)$ were seen as predominant among female genital involvement.

\begin{tabular}{|c|c|c|c|}
\hline Genital Lesions & Total (\%) & Male (\%) & \begin{tabular}{|c|} 
Female \\
$(\%)$
\end{tabular} \\
\hline Scabies & $(30.76)$ & $8(40)$ & - \\
\hline Vitiligo & $4(15.38)$ & $4(20)$ & - \\
\hline Molluscum contagiosum & $2(7.69)$ & $2(10)$ & - \\
\hline Psoriasis & $1(3.84)$ & $1(5)$ & - \\
\hline Lichen planus & $3(11.53)$ & $3(15)$ & - \\
\hline Fixed drug eruptions & $1(3.84)$ & $1(5)$ & - \\
\hline TEN & $2(7.69)$ & - & $2(33.33)$ \\
\hline Acrochordons & $4(15.38)$ & $1(5)$ & $3(50)$ \\
\hline Syringomas & $1(3.84)$ & - & $1(16.66)$ \\
\hline Total & $26(100)$ & $20(76.93)$ & $6(23.07)$ \\
\hline
\end{tabular}




\begin{tabular}{|c|c|c|c|}
\hline $\begin{array}{l}\text { Genital } \\
\text { Lesions }\end{array}$ & Total (\%) & Male (\%) & Female (\%) \\
\hline Vitiligo & $8(38)$ & $5(35.71)$ & $3(42.8)$ \\
\hline $\begin{array}{l}\text { Pemphigus } \\
\text { vulgaris }\end{array}$ & $8(38)$ & $4(28.57)$ & $4(57.14)$ \\
\hline $\begin{array}{l}\text { Fixed drug } \\
\text { eruption }\end{array}$ & $3(14.2)$ & $3(21.42)$ & - \\
\hline Lichen planus & $2(9.52)$ & $2(14.28)$ & - \\
\hline Total & $21(100)$ & $14(66.66)$ & $7(33.33)$ \\
\hline \multicolumn{4}{|c|}{$\begin{array}{c}\text { Table 5. Distribution of Non-Venereal Lesions involving } \\
\text { Oro-Genital Area }\end{array}$} \\
\hline
\end{tabular}

Lesions involving oro-genital involvement predominantly included vitiligo and pemphigus vulgaris in 8 patients each (38\%) followed by fixed drug eruptions in $3(14.2 \%)$ and lichen planus in 2 (9.52\%).

\begin{tabular}{|c|c|c|c|}
\hline Genital Lesions & Total (\%) & Male (\%) & Female (\%) \\
\hline Lichen planus & $5(45.45)$ & $5(55.55)$ & - \\
\hline Vitiligo & $2(18.18)$ & $2(22.22)$ & - \\
\hline $\begin{array}{l}\text { Fixed drug } \\
\text { eruption }\end{array}$ & $2(18.18)$ & $2(22.22)$ & - \\
\hline $\begin{array}{l}\text { Pemphigus } \\
\text { vulgaris }\end{array}$ & $2(18.18)$ & - & $2(100)$ \\
\hline Total & $11(100)$ & $9(81.81)$ & $2(18.18)$ \\
\hline \multicolumn{4}{|c|}{$\begin{array}{l}\text { Table 6. Distribution of Non-Venereal Lesions involving } \\
\text { Oro-Genital and Skin }\end{array}$} \\
\hline
\end{tabular}

Only 11 patients were found to have concurrent orogenital and skin involvement, of which $5(45.45 \%)$ cases of lichen planus and 2 (18.18) cases each of vitiligo, fixed drug eruption and pemphigus vulgaris were observed.

\section{Distribution of Non-Venereal Genital Dermatoses based on Aetiology \\ In this study a total of 20 different types of non-venereal genital diseases were studied, which are broadly classified into benign conditions including normal variants, inflammatory conditions, infections and infestations and miscellaneous diseases. The most common disorder was genital vitiligo, which accounted for 21 patients (21\%) followed by scabies in 19 (19\%) and Lichen planus in 10 $(10 \%)$. The other major disorders encountered included pemphigus vulgaris in $10(10 \%)$, FDE in $8(8 \%)$, pearly penile papules and LSEA each in $5(5 \%)$ patients. Scabies 19 (24.35\%) and genital vitiligo 15 patients $(19.23 \%)$ were the two most common disorders seen in the male population, whereas genital vitiligo in $6(27.27 \%)$ and pemphigus vulgaris in $6(27.27 \%)$ were common disorders seen among female population.}

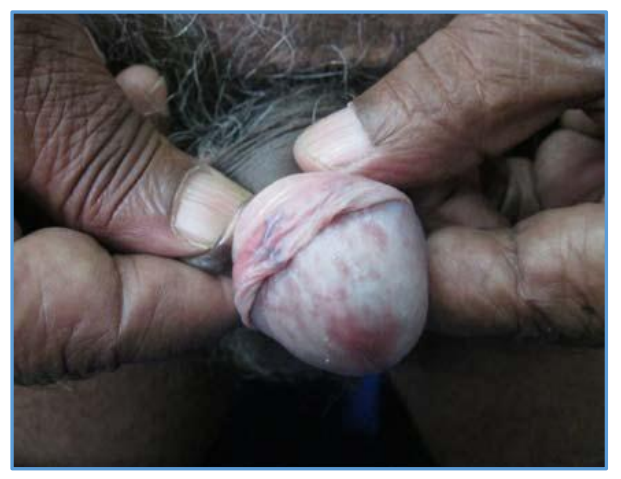

Figure 1. Candidal Balanoposthitis

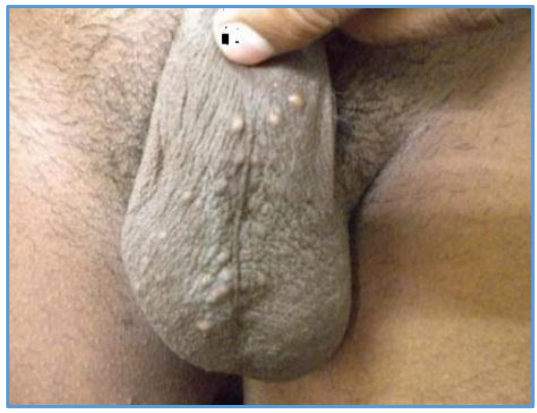

Figure 2. Multiple Sebaceous Cysts

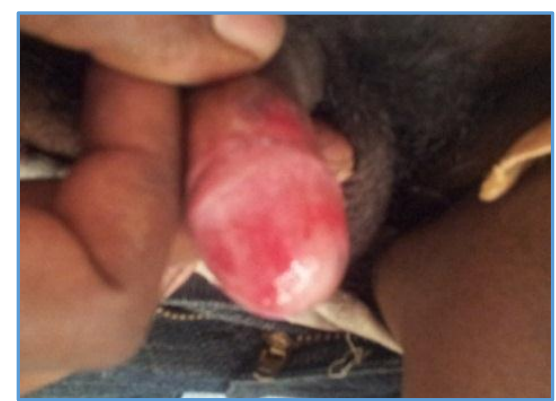

Figure 3. Zoon's Balanitis

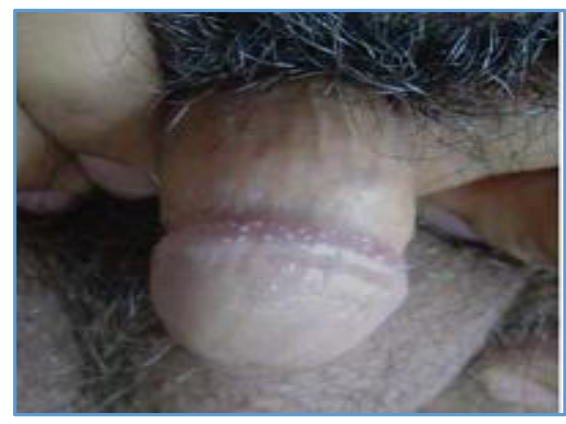

Figure 4. Pearly Penile Papules

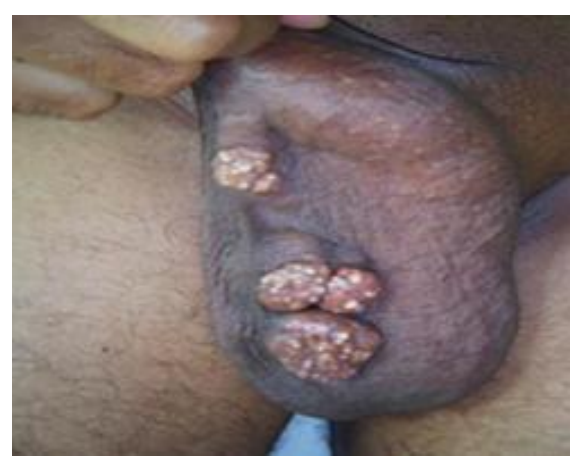

Figure 5. Scrotal Calcinosis

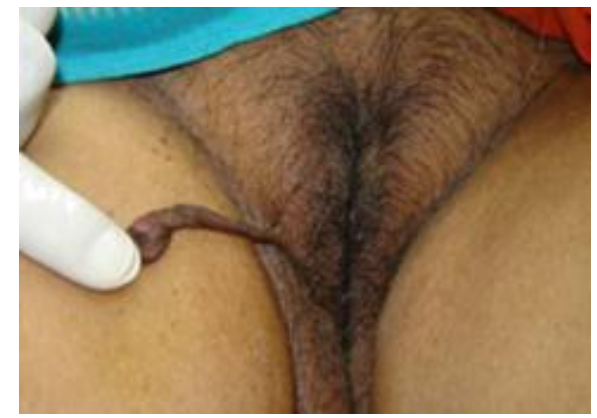

Figure 6. Acrochordon 


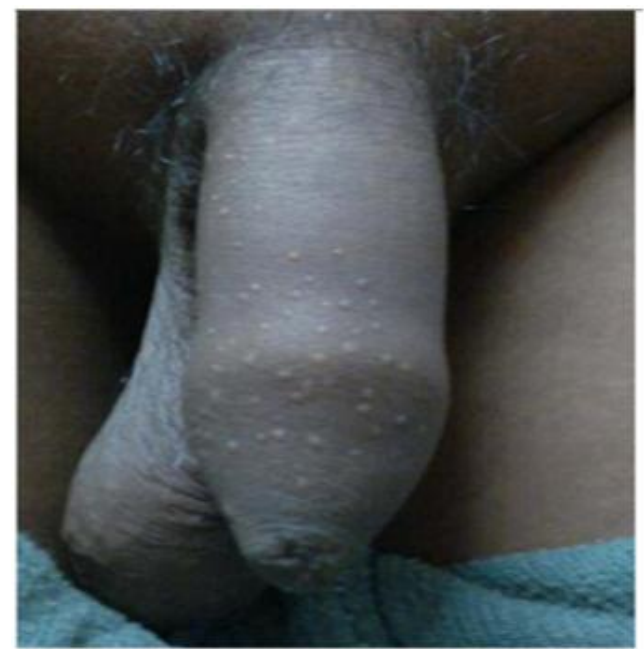

Figure 7. Lichen nitidus

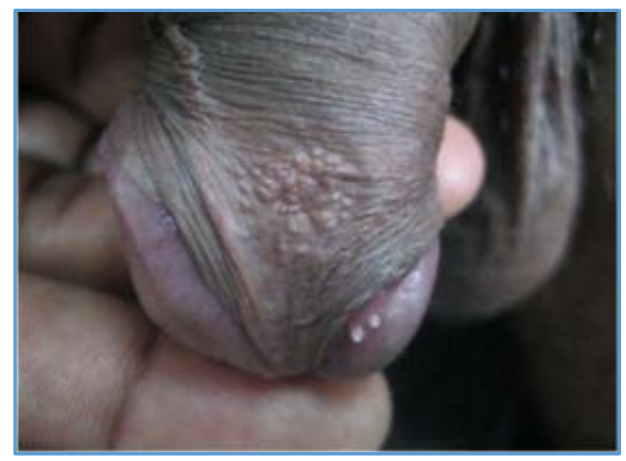

Figure 8. Fordyce Spots

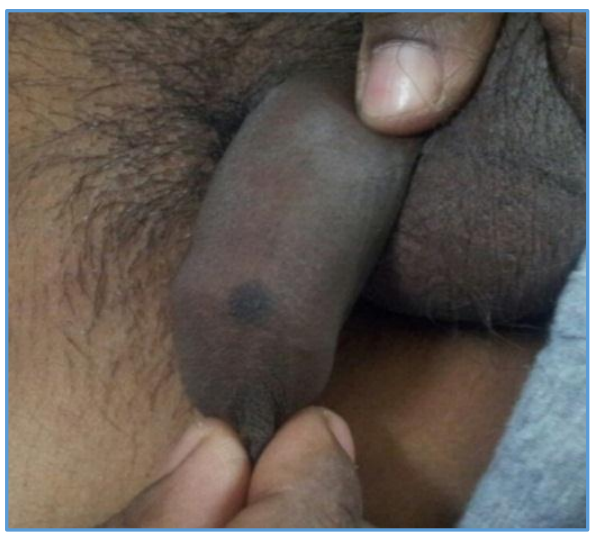

Figure 9. Penile Lentigines

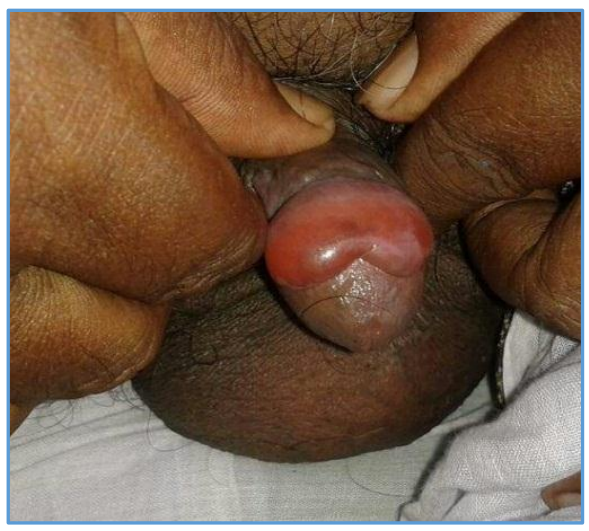

Figure 10. Bullous FDE

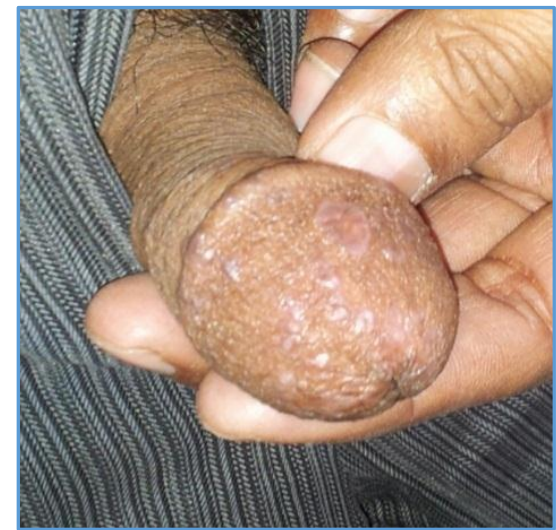

Figure 11. Lichen planus

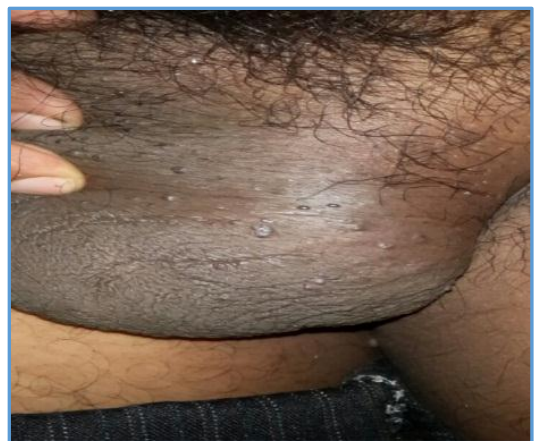

Figure 12. Angiokeratoma of Fordyce
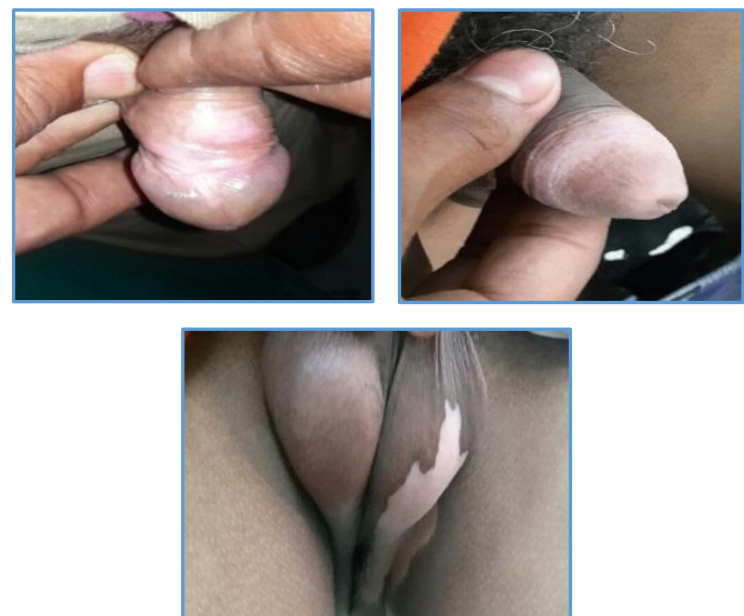

Figure 13A, B, C. Vitiligo on Glans Penis and Scrotum
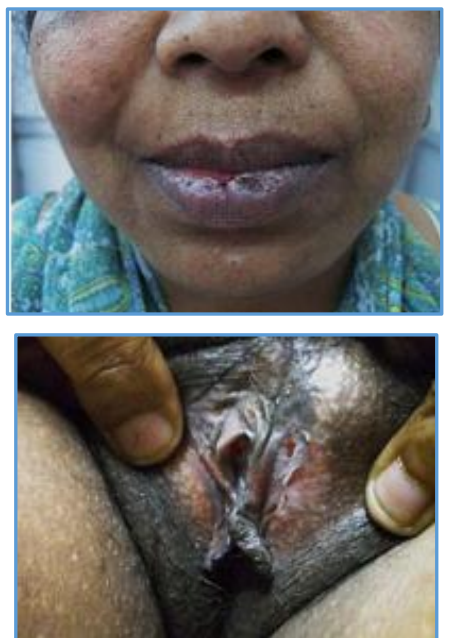

Figure 14A, B. Pemphigus Vulgaris 

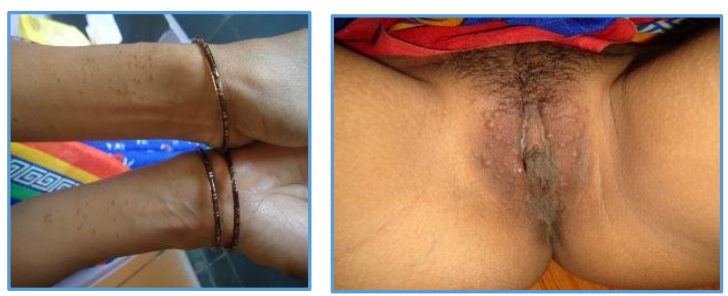

Figure 15A, B. Syringomas

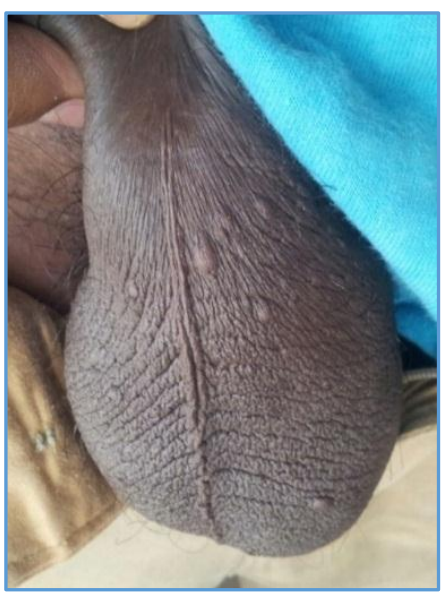

Figure 16. Nodular Scabies

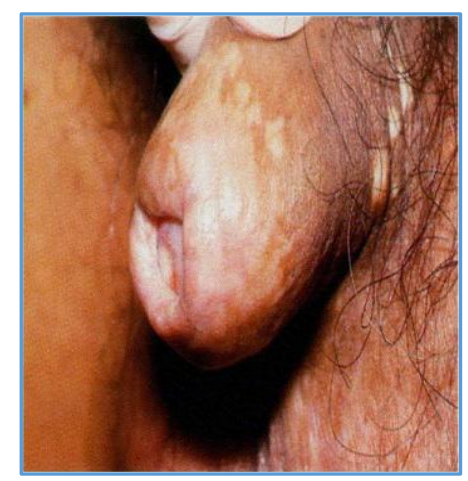

Figure 17. BXO

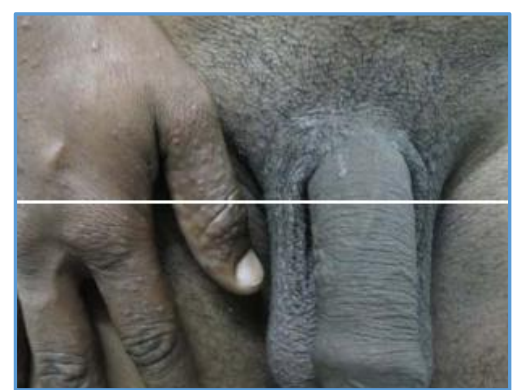

Figure 18. Scabies

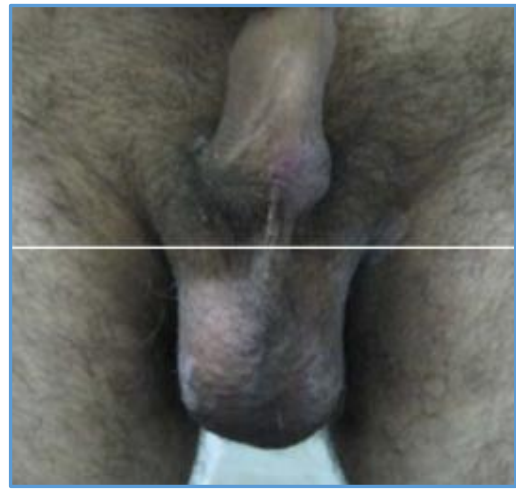

Figure 19. Psoriasis

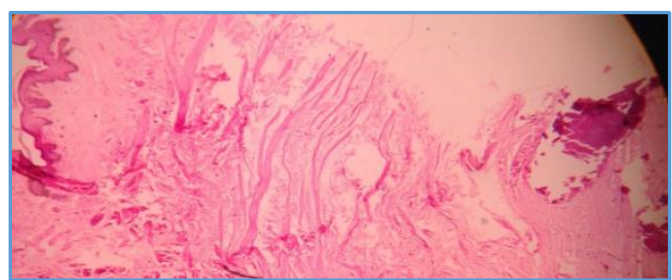

Figure 20. Histopathology of Scrotal Calcinosis

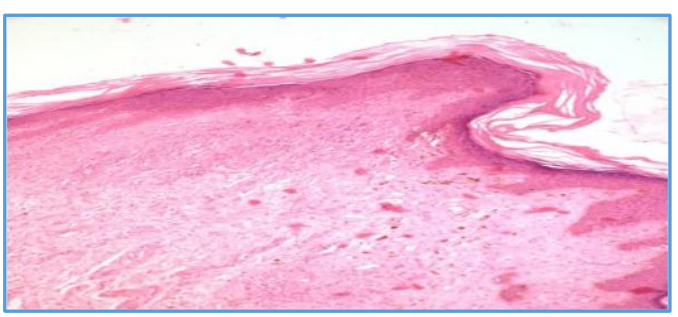

Figure 21. Histopathology of BXO

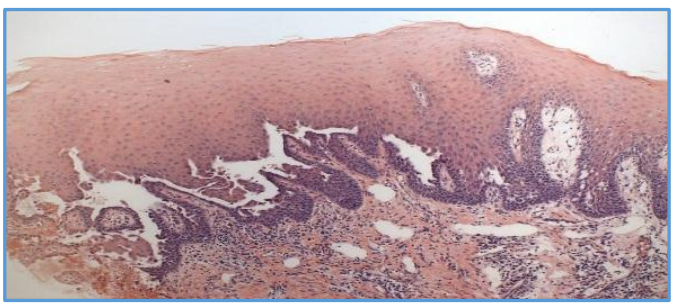

Figure 22. Histopathology of Pemphigus Vulgaris

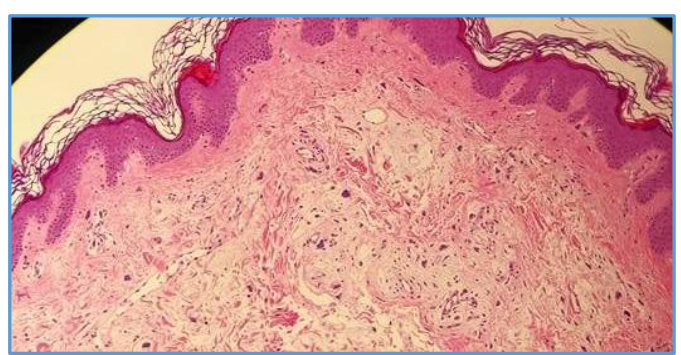

Figure 23. Histopathology of Acrochordons

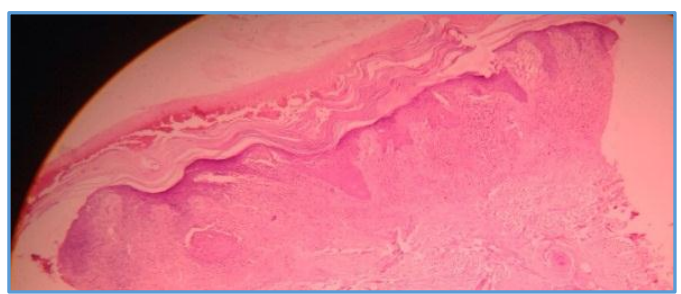

Figure 24. Histopathology of Lichen planus

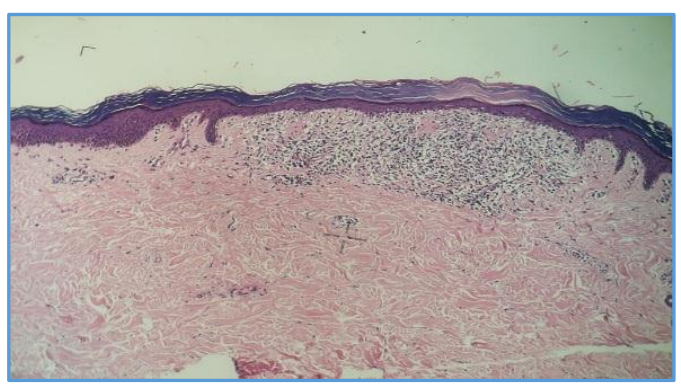

Figure 25. Histopathology of Lichen nitidus 


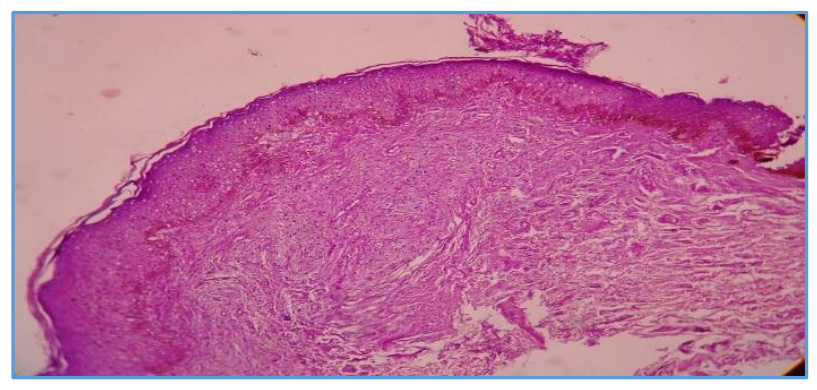

Figure 26. Histopathology of Pearly Penile Papule

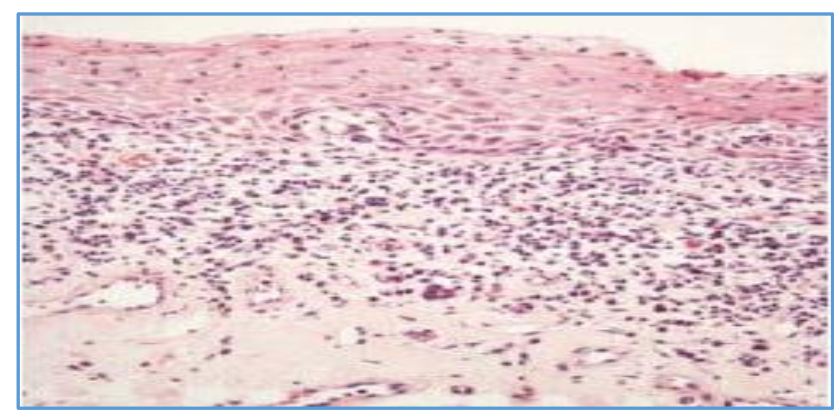

Figure 27. Histopathology of Zoon's Balanitis

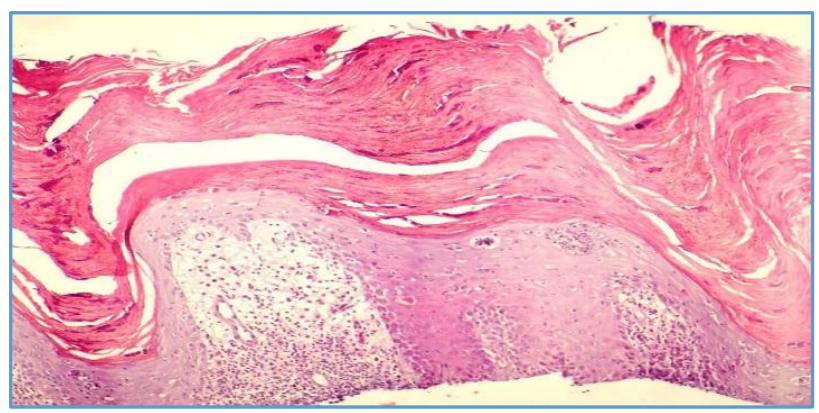

Figure 28. Histopathology of Psoriasis

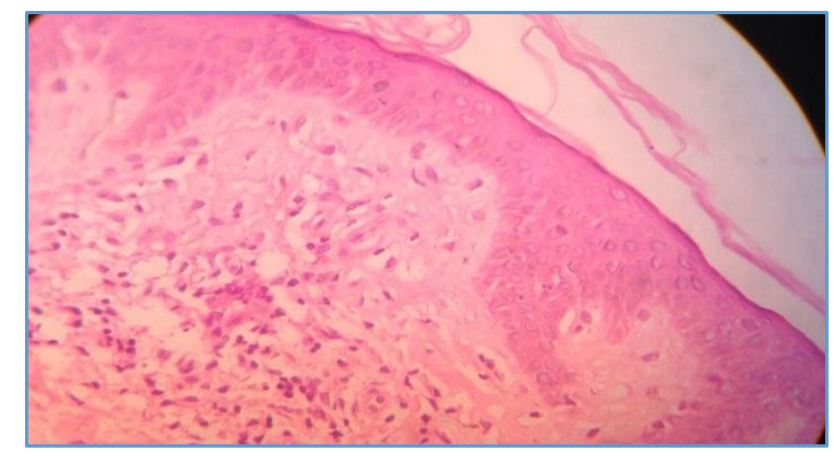

Figure 29. Histopathology of Vitiligo

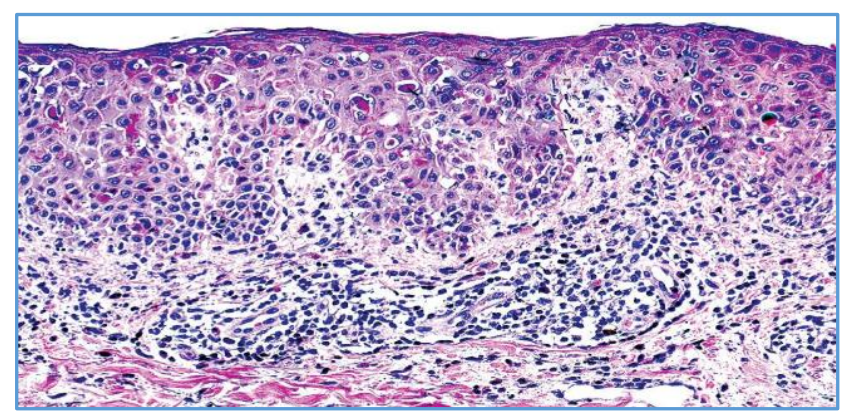

Figure 30. Histopathology of FDE

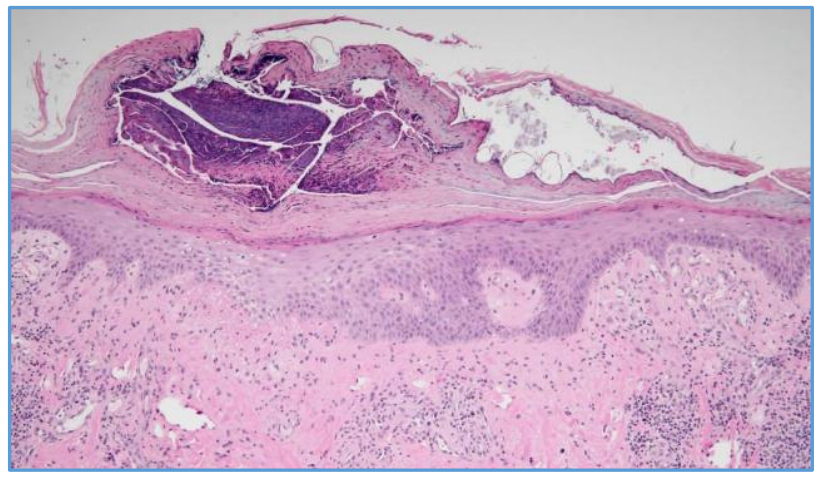

Figure 31. Histopathology of Scabies

\section{DISCUSSION}

Age

In the present study, more number of patients belonged to the age group of 31 - 40 years ( 25 cases), followed by 41 - 50 years ( 23 cases) and 51 - 60 years (20 cases), least incidence was observed in 1 - 10 years ( 1 case each).

Sex

In the present study, out of 100 patients there were 78 males (78\%) and 22 females (22\%).

\section{Discussion of Individual Dermatoses Vitiligo}

In the present study, vitiligo was seen in 21 patients (21\%) out of which there were 15 males and 6 females. The malefemale ratio was 2.5: 1 . Out of 21 patients, oro-genital vitiligo was seen in 8 patients followed by 7 patients, in which only genitals were involved.

In our study, all vitiligo patients were complaining of asymptomatic white patches. Biopsy were done in 15 patients and two biopsy specimens were taken from patients who were having concurrent oro-genital and skin involvement. Histopathologically, all patients showed either decrease or complete absence of melanocytes in the basal layer. ${ }^{2}$

\section{Scabies}

In the present study scabies were seen in 19 patients (19\%), out of which all patients were males. The highest age of onset being 66 yrs. and least being 11 yrs., indicating that scabies is common among extremes of ages. Out of 19 patients, only genital scabies involving scrotum and penis were seen in 11 patients and genitals and skin involvement were seen in remaining patients. Histopathologically, Mast cells and Eosinophils in dermis was seen in one patient which were common for many Arthropod reactions identical with features mentioned in Fernandez $\mathrm{N}$ et al- Pathological findings in human scabies. ${ }^{3}$ All patients showed Hyperkeratosis, Spongiosis, Acanthosis and Dermal Lymphocyte infiltration which were consistent with features of non-specific dermatitis. ${ }^{4}$ Burrow with mite and lifting of stratum corneum was seen in 2 patients which were diagnostic of scabies, which were identical with the features mentioned in Lever WF et al- Histopathology of scabies study.5,6

\section{Lichen Nitidus}

In our study, Lichen nitidus were seen in two male patients. Both the patients were complaining of asymptomatic skin 
coloured lesions on shaft of penis. Histopathologically, all patients showed Acanthosis and Lymphocyte infiltration in dermis along with elongation of rete ridges and mild histiocyte infiltration.

\section{Pemphigus Vulgaris}

In the present study Pemphigus vulgaris were seen in $10(10 \%)$ patients, out of which 6 patients were males and 4 patients were females. In 8 patients, oro-genital involvement was seen and in 2 patients concurrent oro-genital skin involvement were seen.

\section{Fixed Drug Eruption}

In present study fixed drug eruption were seen in 8 (8\%) patients, out of which all patients were males. Only genital involvement in 2 patients, genital and skin in 1 patient, orogenital involvement in 3 patients and concurrent oro-genital and skin involvement in 2 patients were seen. ${ }^{7}$

\section{Pearly Penile Papules}

In present study, pearly penile papules were seen in $5(5 \%)$ patients and all the patients were complaining of asymptomatic raised lesions over coronal sulcus.

Histopathologically, there were no epidermal changes and dermal changes included increased fibroblasts proliferation and thin walled blood vessels in dermis in all the patients. ${ }^{8}$

\section{Acrochordons}

In present study, Acrochordons were seen in $4(4 \%)$ patients of which 3 were females and 1 male. Both genital and skin involvement were seen in all patients. All patients were complaining of asymptomatic skin coloured lesions.

Histopathologically, all the patients showed Acanthosis and loosely arranged collagen fibres in dermis. Papillomatosis is seen in one patient.

\section{Lichen planus}

In present study Lichen planus were seen in $10(10 \%)$ patients, out of which genital and skin involvement were seen in 3 patients, oro-genital in 2 patients and concurrent orogenital and skin in 5 patients.

Histopathologically, all patients showed hypergranulosis, acanthosis, dermal lymphocytic infiltration and basal cell degeneration. Civatte bodies are seen in 3 patients. Pointed rete ridges are seen in four patients. ${ }^{9}$

\section{Angiokeratoma of Fordyce}

In present study, Angiokeratoma of Fordyce were seen in one patient. Chief complaint was asymptomatic raised lesions over scrotum. On clinical examination, multiple tiny papules were seen over scrotum.

Histopathological examination revealed hyperkeratosis, parakeratosis and acanthosis. Dilated upper dermal blood vessels are seen. ${ }^{10}$

\section{Syringoma}

In present study, Syringomas were seen in one patient. Chief complaint was asymptomatic skin coloured lesions over wrist and pubis. On clinical examination, multiple skin coloured papules were seen over vulva and wrist. As it is the unusual location for syringomas, other differential diagnosis like plane warts and plane xanthomas were also considered.
Histopathological examination showed epithelial neoplasm involving the upper reticular dermis made up of solid epithelial islands and ductal structures. The ductal structures are lined by two or three layers of cuboidal cells. The same cells present within solid cords show attempt towards ductal differentiation. The stroma is made up of thickened bundles of collagen.

\section{Balanitis xerotica obliterans}

In present study, BXO was seen in one patient with complaints of non-pruritic white spots on the preputial skin and narrowing of preputial orifice with inability to retract since 3 years. Local examination revealed ivory-white atrophic macules, 2 to $5 \mathrm{~mm}$ in diameter involving the skin of the prepuce near its opening. Histopathological examination revealed Hyperkeratosis, thin and atrophic stratum malpighii, hydropic degeneration of basal layer, absent rete ridges, oedema and hyalinisation of collagen below the epidermis. Band like inflammatory infiltrate was seen below the epidermis and in the lower dermis. ${ }^{11}$

\section{Lichen sclerosus et atrophicus}

In present study, LSA were seen in 4 (4\%) female patients. The major complaint was asymptomatic or mildly pruritic white patch over vulva.11,12,13 The highest age of onset was 65 years and least being 53 years.

Histopathologically, all 4 patients showed epidermal atrophy, hydropic degeneration of basal layer, lymphocytic infiltration of dermis and collagen homogenisation. Out of 4 patients, one patient showed flattening of rete ridges and histiocytes in papillary dermis indicating features of early LSA. ${ }^{14,15,16}$

\section{Penile lentigines}

In present study, penile lentigines were seen in one patient complaining of black coloured lesions over penis. On clinical examination, multiple hyperpigment macules were seen over shaft of penis.

On biopsy, histopathological examination revealed acanthosis, elongation of rete ridges with increased melanin at the tips of rete pegs and dermal lymphocytic infiltration. ${ }^{17}$

\section{Zoon's Balanitis}

In present study, Zoon's Balanitis were seen in 2 (2\%) patients. Both were complaining of red lesions over glans penis. On clinical examination, single red glistening plaque on glans penis.

In our study, biopsy was done in two patients and histopathology report showed dermal lymphocytic, eosinophil and plasma cell infiltration. There were no epidermal changes noted. One patient showed extravasated RBCs. $18,19,20$

\section{Scrotal calcinosis}

In present study, one patient presented with asymptomatic swellings over scrotum. On clinical examination, multiple irregular skin coloured non-tender hard nodules with yellowish and chalky white deposits were seen.

Excision biopsy was done, and histopathology report revealed deposits of calcium in dermis and mild histiocyte infiltration. ${ }^{21}$ 


\section{Psoriasis}

In present study, Psoriasis was seen in one patient with complaints of itchy scaly lesions on palms and penis. On clinical examination, scaly plaques were seen on palms and penis.

Skin punch biopsy was done, and histopathology report showed hyperkeratosis, parakeratosis, acanthosis and absent granular layer. Dilated capillaries were seen in upper dermis. $^{22}$

\section{Sebaceous Hyperplasia/ Fordyce Spots}

In present study, $\mathrm{SH}$ is seen in $3(3 \%)$ patients. All the patients presented with Asymptomatic raised lesions over penis. All the patients were biopsied where punch biopsy included one yellow papule. Histopathology report of all 3 patients revealed lobulated lesion composed of enlarged sebaceous gland. In one patient cells displayed foamy, vesicular cytoplasm indicating mature sebocytes.

\section{Sebaceous Cyst}

In present study, only one case of sebaceous cyst was seen with complaints of asymptomatic swelling over scrotum. On excision biopsy showed typical histopathological features. ${ }^{23,24}$

\section{CONCLUSION}

The study was quite useful in understanding the clinical, aetiological and pathological characteristics of various types of non-venereal genital dermatoses. True prevalence and pattern can be known only with interaction from various departments.

In the present study, there was a high correlation with confirmation of clinical diagnosis to histological diagnosis except in two cases where the findings resulted in a change in the diagnosis. In both these cases, a clinical diagnosis of scabies was made and in both of them features of non-specific dermatitis were present histologically.

In the present study, most patients with the inflammatory penile disease such as Psoriasis and Lichen planus have cutaneous signs at extragenital sites and a full examination enables a firm diagnosis, which may obviate the need for biopsy. The presence of extragenital cutaneous inflammatory skin disease helps in the evaluation of the clinical diagnosis.

Most dermatoses of the genitalia are amicable to clinical diagnosis based on classic dermatological grounds of full history taking and complete physical examination. Biopsies need not be performed routinely, although they may be useful in confirming the clinical diagnosis. Secondly, a histological diagnosis may be valuable in advancing patient managementfor example, increasing the authority with which surgery is advocated in diseases such as Lichen sclerosus and Zoon's balanitis where circumcision may be necessary.

\section{REFERENCES}

[1] Acharya KM, Ranpara H, Sakhia JJ, et al. A study of 200 cases of genital lesions of non-venereal origin. Indian J Dermatol Venereol Leprol 1999;64(2):68-70.

[2] Weedon D. Skin pathology. 2nd edn. Edinburgh: Churchill Livingstone 2002.

[3] Fernandez N, Torres A, Ackerman AB. Pathological findings in human scabies. Arch Dermatol 1977;113(3):320-4
[4] Lever WF, Lever GS. Histopathology of scabies, in: Histopathology of the skin. $7^{\text {th }}$ edn. J.B. Lippincott Company 1990: p. 238.

[5] Falk ES, Eide TJ. Histologic and clinical findings in human scabies. Int J Dermatol 1981;20(9):600-5.

[6] Fernandez N, Torres A, Ackerman AB. Pathologic findings in human scabies. Arch Dermatol 1977;113(3):320-4.

[7] Nussinovitch M, Prais D, Ben-Amitai D, et al. Fixed drug eruption in the genital area in 15 boys. Pediatr Dermatol 2002;19(3):216-9.

[8] Sonnex C, Dockerty WG. Pearly penile papules: a common cause of concern. Int J STD AIDS 1999;10(11):726-7.

[9] Scully C, el-Kom M. Lichen planus: review and update on pathogenesis. J Oral Pathol 1985;14(6):431-58.

[10] Miller C, James WD. Angiokeratoma of Fordyce as a cause of red scrotum. Cutis 2002;69(1):50-1.

[11] Kyriakis KP, Emmanuelides S, Terzoudi S, et al. Gender and age prevalence distributions of morphea en plaque and anogenital lichen sclerosus. J Eur Acad Dermatol Venereol 2007;21(6):825-6.

[12] Campus GV, Alia F, Bosincu L. Squamous cell carcinoma and lichen sclerosus et atrophicus of the prepuce. Plast Reconstr Surg 1992;89(5):962-4.

[13] Powell J, Robson A, Cranston D, et al. High incidence of lichen sclerosus in patients with squamous cell carcinoma of the penis. Br J Dermatol 2001;145(1):859.

[14] Micali G, Nasca MR, Innocenzi D. Lichen sclerosus of the glans is significantly associated with penile carcinoma. Sex Transm Infect 2001;77(3):226.

[15] Mehregan AH, Hashimoto K. Lichen sclerosus et atrophicus. In: Pinkus' guide to dermatohistopathology. $5^{\text {th }}$ edn. East Norwalk: Appleton \& Lange, Prentice-Hall International 1991:357-8.

[16] Frances C, Wechsler J, Meimon G, et al. Investigation of intercellular matrix macromolecules involved in lichen sclerosus. Acta Derm Venereol 1983;63(6):483-90.

[17] Bunker CB, Neill SM. The genital, perianal and umbilical regions. In: Burns T, Breathnach S, Cox N, et al, eds. Rook's textbook of dermatology. $7^{\text {th }}$ edn. Oxford: Blackwell Science 2004:68.1-68.83.

[18] Souteyrand P, Wong E, MacDonald DM. Zoon's balanitis (balanitis circumscripta plasmacellularis). $\mathrm{Br}$ J Dermatol 1981;105(2):195-9.

[19] Thomson MA, Carr RA, Ganesan R, et al. Extensive mucinous metaplasia of the vulva arising within Zoon's vulvitis. Br J Dermatol 2007;156(4):750-2.

[20] Waugh MA. Balanitis. Dermatol Clin 1998;16(4):75762.

[21] Hutchinson J. Sebaceous gland tumours in the scrotum. Plate LXVIII. Illustrations of Clinical Surgery. Vol. 2. Philadelphia: Blakiston Son \& Co 1888: p.22.

[22] Bunker CB. Male genital skin disease. London: Saunders 2004.

[23] Weedon D. Skin pathology. 2nd edn. Edinburgh: Churchill Livingstone 2002.

[24] Kirkham N. Tumors cysts of the epidermis. In: Elder DE, Elenitsas R, Johnson BL, et al, editors. Lever's histopathology of the skin. $10^{\text {th }}$ edn. South Asian: Lippincott Williams Wilkins 2009:791-849. 